\title{
ANAESTHESIA FOR OCCIPITAL ENCEPHALOCOELE
}

\author{
R.E. Creighton, M.D., F.R.C.P. (c), J.E.S. Relton, M.B., F.F.A.R.c.s.(Eng.), F.R.c.P.(c), \\ AND H.W. MERIDY, M.D., F.A.C.A. ${ }^{*}$
}

OCCIPITAL ENCEPHALOCOELE is an uncommon congenital malformation occurring on the average once in 5,000 live births, with some demographic variation. The purpose of this report is to describe the anaesthetic problems encountered over a 10-year period in a series of these cases and describe how these problems were managed,

\section{Clinical Material}

Thirty-one patients with a posterior encephalocoele were operated on between 1960 and 1970 at The Hospital for Sick Children, Toronto. Their ages at the time of operation was less than 24 hours in two cases; from 24 hours to one week in seven cases; from one week to one month in six cases; from one month to six months in 11 cases; and over six months in five cases. None of these children died. Ten recovered completely following surgery. The remaining 21 had residual neurological abnormalities such as hydrocephalus, mental retardation, convulsive disorders, blindness and deafness.

\section{Morphology}

In a morphological study of five cases of occipital encephalocoele, Karch et al. ${ }^{1}$ found the malformation to be complex In addition to the bony defect and herniation of the occipital lobes (Figure 1), extensive malformations may occur throughout the neuraxis and involve the mid-brain, the commissural system, the optic pathway, the venous drainage and the base of the skull. Disturbances of central autonomic control, exemplified by a defective temperature regulating mechanism, may occur. These authors suggest that these extensive malformations render the encephalocoele not amenable to surgery. Other congenital anomalies not always confined to the nervous system occur in over 50 per cent of cases. In a review of 66 cases, Hendrick et al." drew attention to a tetrad of co-existent anomalies, occipital encephalocoele, hydrocephalus, Klippel-Feil deformity (cervical vertebral synostosis and neck webbing) and cleft lip or palate in five cases in complete form and in a further six cases in incomplete form.

In the 31 patients under review, the Klippel-Feil syndrome was present in eight cases, six of whom also had cleft palate. Other abnormalities included microgna-

From the Department of Anaesthesia, University of Toronto, and The Hospital for Sick Children, Toronto, Canada.

"Present address the Department of Anaesthesiology, Hartford Hospital, Hartford, Conn., U.S.A.

Address for Reprints: R.E. Creighton, M.D., F.R.C.P.(C), Department of Anaesthesia, The Hospital for Sick Children, 555 University Avenue, Toronto, Ontario, M5G 1X8 Canada.

Canad. Anaesth. Soc. J., vol. 21, no. 4, July 1974 


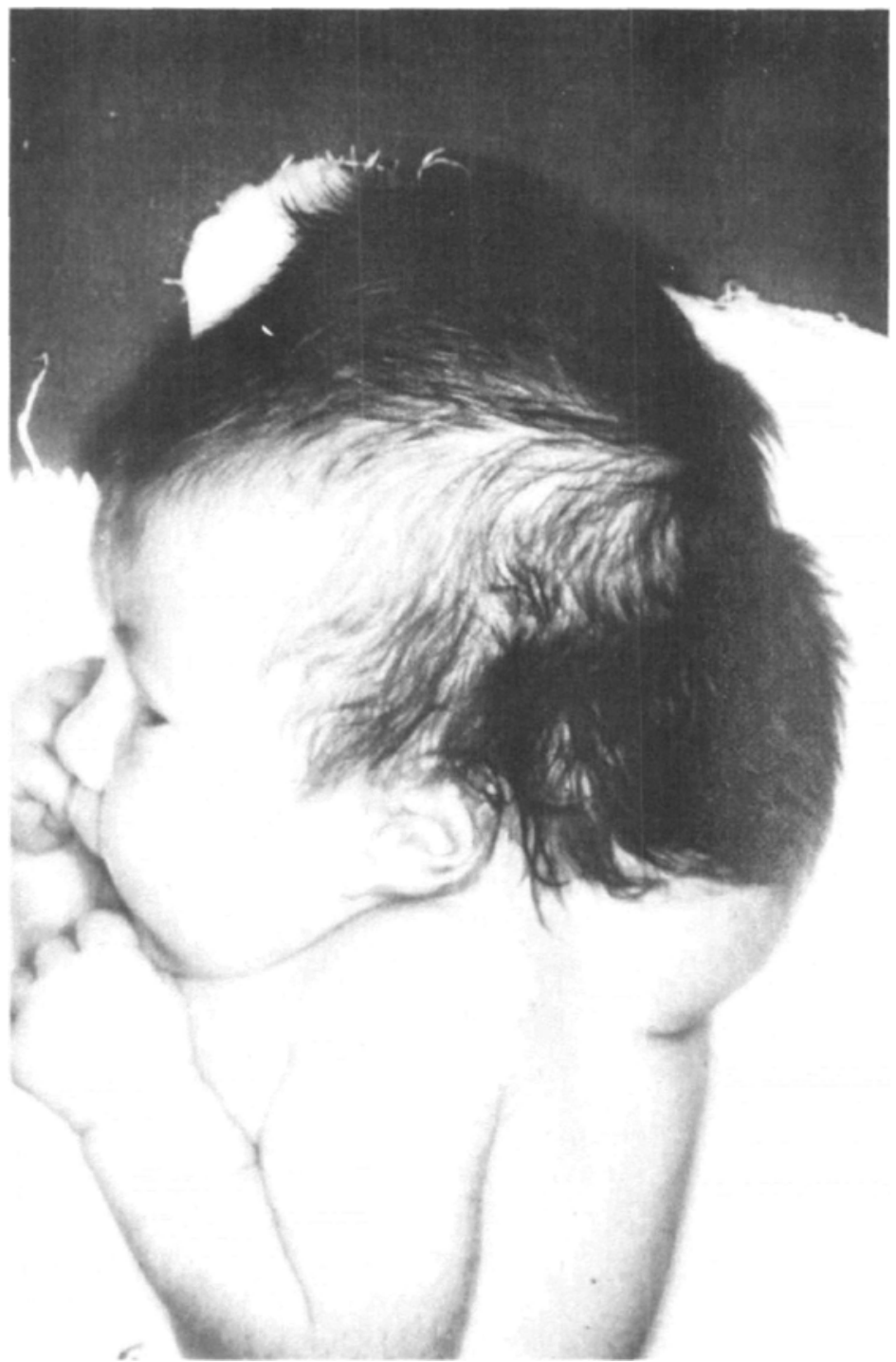

Ficune 1. Occipital Encephalocoele with Klippel-Feil Syndrome.

thia; a common cerebral ventricle with agenesis of the corpus callosum and septum pellucidum; and one each with subglottic stenosis, ventricular septal defect, patent ductus arteriosus, diastematomyelia, lumbar meningocele and spina bifida occulta.

\section{ANaEsThetic Management}

Premedication and Induction. Atropine sulphate $(0.02 \mathrm{mg} / \mathrm{kg})$ was given before operation to all patients. Those under one month of age were pre-oxygenated and intubated before induction of anaesthesia. Older patients were induced with intravenous thiopentone with succinylcholine to facilitate intubation.

Intubation. Armoured tracheal tubes of suitable size were unavailable for the 
earlier cases in this series and therefore naso-tracheal tubes were used to prevent tube kinking when the patient was placed in the prone position. Intubation was performed with the patient lying on his left side. Although it is possible to support the patient supine on bolsters without damage to the encephalocoele, the risk is minimized by using the lateral position. For awake intubation in infants the anaesthetic assistant is instructed to press the shoulders back while supporting the head in the optimum position for laryngoscopy. Although intubation might be difficult because of the encephalocoele, the Klippel-Feil deformity and cleft palate, with the position we used we had no problems.

Maintenance. Nitrous oxide and oxygen supplemented by halothane and trilene was used in 21 cases. Halothane alone was used as a supplement in six cases and diethyl ether in four cases.

Monitoring. To monitor cardiovascular status and temperature an oesophageal stethoscope, blood pressure cuff with oscillometer, ECG and rectal thermistor were used in all cases.

Temperature Control. The maintenance of body temperature was a serious problem in these patients. Lack of central autonomic control may occur with cerebral malformation. The effect of any defect in the temperature regulating mechanism is compounded by the operating room environment where air-conditioning, exposure of the patient, delay in positioning, separation of the patient from the heating blanket by bolsters, loss of heat with a high flow Ayre's T-piece system, cool skinpreparation solutions and the liberal use of saline for wound irrigation combine to increase heat loss.

Using an overhead infra-red heating lamp during the preparatory stages and heating blankets during the operation help to maintain body temperature. Nonetheless, it fell in all the cases in this series and in 6 cases this fall exceeded $3^{\circ} \mathrm{C}$.

Ventilatory Pattern and Posture. The prone position is preferred for posterior fossa surgery in infants. Spontaneous ventilation is desirable as a monitor of brain stem integrity. The use of this position combined with the depressant effect of anaesthetic agents imposes a burden on the relatively immature infant respiratory system. In these circumstances, spontaneous ventilation may be inadequate for satisfactory gas exchange. Thus controlled ventilation was used in 11 cases in this series.

The use of the prone position confers an additional disadvantage during surgery. Any external pressure on the anterior abdominal wall is transmitted to the inferior vena cava and may divert the venous return from the lower part of the body into the vertebral venous plexuses. This effect tends to increase blood loss from the operative site. Meticulous attention must therefore be given to the positioning of the patient. Transverse bolsters under the chest and pelvic girdle ensure that the abdomen remains free from external pressure, permitting unimpeded movement.

Fluid Therapy. In infants the sub-occipital bone is richly vascularised and the dural sinuses are extensive and undefined. The persistence of foetal vasculature increases the blood loss in posterior fossa surgery. ${ }^{1}$ Measurements of this loss were impossible because of the use of large volumes of irrigating fluid and the difficulty of assessing losses on the drapes. However, losses were estimated by observation and by changes in the patient's vital signs. Blood was replaced in an amount suff- 
cient to maintain a systolic blood pressure of $60 \mathrm{mmHg}$ during surgery. Maintenance fluid therapy consisted of glucose 5 per cent in water or glucose 5 per cent in 0.2 per cent saline at a rate of 2 to $5 \mathrm{ml} / \mathrm{kg} /$ hour.

\section{SUMMARY}

Anaesthesia for correction of occipital encephalocoele is often complicated by the presence of hydrocephalus, Klippel-Feil deformity and cleft palate. In a series of 31 cases the prone position for surgery was maintained by bolsters placed so that abdominal movement was unimpeded. The body temperature fell in all cases despite the use of heating blankets and infra-red lamps. Because precise measurements of blood loss were impossible, sufficient blood was transfused to maintain a systolic blood pressure of $60 \mathrm{mmHg}$. With these anaesthetic techniques all patients survived the operation.

\section{RÉsUMÉ}

La conduite anesthésique pour correction d'encéphalocèle occipitale doit tenir compte souvent d'une anomalie associée, telle d'hydrocéphalie, le syndrome de Klippel-Feil ou la fissure palatine. Les auteurs, dans une série de 31 cas, recommandent l'emploi de supports coussinés pour ne pas augmenter la pression intraabdominale. On a pu noter une baisse de la température corporelle malgré l'emploi de matelas chauffants et de lampes à rayons infrarouges. Puisqu'il était difficile d'apprécier avec exactitude les pertes sanguines, on infusa du sang que pour maintenir la pression systolique au-dessus de $60 \mathrm{~mm}$ de $\mathrm{Hg}$. Tous les patients ont survécu à l'intervention.

\section{ACKNOWLEDGMENT}

The authors acknowledge the assistance of Dr. E.B. Hendrick, Dr. H.J. Hoffman, and Dr. R.P. Humphreys under whose care these patients were admitted.

\section{REFERENCES}

1. Karch, S.B. \& Urich, H. Occipital encephalocele: a morphological study. J. Neurol. Sci, 15: 89 (1972).

2. Hendrick, E.B., Hoffrian, H.J., \& Hugenholtz, H. Occipital encephalocele, hydrocephalus, Klippel-Feil deformity and cleft palate - a tetrad of anomalies. Proceedings 12th World Federation of Neurological Surgeons. Tokyo, Japan (1973). 